\title{
COMUNICAÇÃO E EDUCAÇÃO: a interação entre cusistas e tutores
}

\author{
Dyolen Emanuel Vieira de SOUZA, e-mail: dougdy@gmail.com ${ }^{1}$ \\ "Com pedaços de mim eu monto um ser atômico" (2006, p. 37)².
}

\section{RESUMO}

A pesquisa visa analisar a interação entre cursistas e tutores no Núcleo de Educação Aberta e a Distância - NEAD/UFMT. Em que medida o Núcleo garante a qualidade da construção de sentidos entre professores e alunos, ou seja, no processo de ensino/ aprendizagem? A investigação é uma análise cultural no campo educativo, priorizando a Linguagem. O componente dialógico - a interação - permite a compreensão que circunscreve às complexas formas de comunicação da contemporaneidade, destacando o papel das mediações e dos mediadores nas produções de sentidos pretendidos.

Palavras-chave: Comunicação; Cibercultura; Ensino a Distância.

\section{COMUNICATION AND EDUCATION: the iteration between learners and tutors}

\begin{abstract}
This research aims to analyze the interaction between learners and tutors at the Nucleus of Open and Distance Education - NEAD/ UFMT. In what ways does NEAD guarantee the quality of construction of knowledge between teachers and students in the process of teaching/learning? The investigation is based on a cultural analysis in the educational field prioritizing language. The dialogic component - interaction - allows for an understanding that surrounds the complex forms of communication in the contemporary highlighting the functions of the mediations and of the mediators in the productions of intended meanings.
\end{abstract}

Keywords: Communication; Cyberculture; Distance Education.

\section{A construção de sentidos}

A sociedade contemporânea com a fluidez das comunicações, o desenvolvimento das Novas Tecnologias e o veloz incremento do conhecimento, demanda meios variados para a gestão do ensino/ aprendizagem. Como conseqüência, novas formas de convívio social e de interagir com o outro são geradas para (e na) Educação a Distância. Os cursos não-presenciais reinventam os processos de transmissão e recepção das informações. As Novas tecnologias medeiam os processos informacionais e comunicativos da EaD por vias multidirecionais e dialógicas.

Assim, os princípios da pedagogia da transmissão informacional (unidirecional e hierárquica) que regem a educação tornam-se obsoletos. $\mathrm{Na}$ cibercultura, os aspectos distintivos entre a emissão e a recepção das mensagens são superados. Nota-se, que a sociedade necessita de indivíduos com um novo perfil. Sujeitos abertos à mudanças paradigmáticas, em que o conhecimento deixa de ser visto como um produto pronto e acabado para tornar-se transitório e destotalizado.

Envolto a esse fluxo do contemporâneo, a pesquisa se propõe a pensar as relações entre Comunicação, Educação e Novas Tecnologias. Uma análise sobre o

\footnotetext{
${ }^{1}$ Mestrando em Estudos de Cultura Contenporânea (ECCO), pela Universidade Federal de Mato Grosso (UFMT), linha de pesquisa Comunicação e Mediações Culturais. Orientado pela profa. Dra. em Semiótica e docente em Comunicação Social, Lucia Helena Vendrusculo Possari. Membro do Núcleo de Pesquisa em Comunicação (NUCOM-UFMT), em Cuiabá/MT.
} 
ensino/ aprendizagem no Núcleo de Educação Aberta e a Distância - NEAD/UFMT. Problematiza-se: em que medida a modalidade a distância garante a qualidade da construção de sentidos entre professores e alunos, ou seja, no processo de ensino/ aprendizagem? A investigação é uma análise cultural no campo educativo, priorizando a Linguagem.

O NEAD/UFMT engloba o espaço geográfico do estado de Mato Grosso, o terceiro maior estado brasileiro em extensão, com área de $903.358 \mathrm{~km}^{2}$. Diante esses números, o NEAD/ UFMT, desde 1992, objetiva integrar aqueles que moram afastados dos grandes centros urbanos, suprimindo espaços e diluindo distâncias. Para isso, o núcleo possui nove pólos, distribuídos pelas cidades de Cuiabá, Colíder, Diamantino, Juína, Terra Nova do Norte, Sinop, Barra do Garças, Rondonópolis e Várzea Grande, rompendo fronteiras.

Nesse mapeamento movente, os professores e alunos não estão fisicamente juntos, mas corporificados através dos textos e mediados por tecnologias, como a Internet, que permitem a interação. Como mediação, Barbero (2002) o eixo do debate deve se deslocar dos meios para as mediações, isto é, para as articulações entre práticas de comunicação e movimentos sociais, para as diferentes temporalidades e matizes culturais. Barbero afirma ainda, que as mediações não se referem propriamente ao meio, e sim às leituras intermediárias, propiciadas pelas diversas instâncias sociais como a família, a religião, as mídias etc.

Dessa forma, antigos conceitos como os de leitura e leitores passam a ser reconcebidos nesse novo ambiente educacional. Há uma dilatação desses termos. O leitor de livro expande-se para o leitor da imagem e, desta, para o leitor de formas híbridas de signos e processos de linguagem. Segundo Moraes (1997), emerge um paradigma educacional que enfatiza a totalidade indivisa, o pensamento sistêmico e se baseia na compreensão de que o todo só pode ser entendido se relacionado às suas partes, às suas conexões, mediante a complexidade existente entre os fenômenos que o regem.

Morin (1996), trabalhando com essa questão, expõe a teoria da complexidade, segundo a qual um sistema não é apenas um todo constituído de partes, mas é algo que tem qualidades próprias que somente emergem quando o sistema se constitui. Em decorrência disso, a complexidade corporificada na Web contribuiu para a desconstrução da figura milenar de muros, salas-de-aula ou da presença física dos professores, ampliando substancialmente o universo educacional.

As noções de tempo (Kronos e Kairós) e espaço (geográfica e simbolicamente) são remodeladas para essa modalidade de ensino. Por meio de bits, o mundo passa a estar ao alcance do mouse e o ambiente virtual diminui as distâncias entre os indivíduos. O ciberespaço distingue-se dos outros lugares físicos, palpáveis e concretos. Mostra-se como um lugar de atualizações, conexões, nós; no interior do qual criam-se novas possibilidades, recriações, efeitos de sentido e representações; um espaço complexo que está presente em vários lugares e, ao mesmo tempo, em lugar algum - um 'destempo' como denomina Barbero (2006).

O que se realiza no espaço é um viver comum. Espaço seria, esse locus onde são construídos os significados sociais, culturais, a partir dos processos de interlocução, de compartilhamento, de diálogo, de troca entre sujeitos relacionais, situados historicamente. Dessa forma, o espaço deve ser pensado como um espaço de acontecimentos e de ações. Percebe-se, portanto, que todas essas questões apontam para a necessidade das áreas de Comunicação, Cultura e Educação revejam a comunicação de até então. Assim como as discussões acerca da interação e interatividade e, principalmente, da Cultura.

V. $7 \mathrm{~N}^{\mathrm{o}}$ 3, dezembro, 2009 
Sobre cultura, Geertz (1973) a postula como um sistema de signos passíveis de interpretação. Nesse sistema simbólico, a característica fundamental é a capacidade comum da humanidade de atribuir, de forma sistemática, racional e estruturada, significados e sentidos "às coisas do mundo". Essa teia de significações tende ao híbrido, à mescla.

Quanto à cibercultura, Lévy a conceitua como: “o conjunto de técnicas (materiais e intelectuais), de práticas, de atitudes, de modos, de pensamento e de valores que se desenrolam juntamente com o crescimento do ciberespaço" (1999, p. 17). De acordo com André Lemos, a cibercultura caracteriza-se por três "leis" fundadoras: "a liberação do pólo da emissão, o princípio de conexão em rede e a configuração de formatos midiáticos e práticas sociais"”. A tríade emissão, conexão e reconfiguração norteia o processo de "re-mixagem" do contemporâneo, assim como intitula Lemos. Essas características produzem uma mudança social na vivência do espaço e do tempo, determinando as agoridades contemporâneas.

O ciberespaço viabiliza a troca informacional a distância, por meio de ferramentas comunicacionais e informacionais, sem tornar significativo a localização geográfica do enunciador, consolidando uma comunicação destituída de presencialidade corpórea. A comunicação passa a ser de muitos para muitos, ancorada em elementos de convergência e de hipertextualidade. Criam-se cibernarrativas, que geram novos espaços de "socialidade", de enunciação e de autoria. Ações que ocasionam em efeitos de significações, legitimando o ser e o estar on line.

Contudo, essa dinâmica comunicacional causa implicações às Teorias da Comunicação. O clássico tripé emissão-mensagem-recepção, determinado por Jakobson, tem sua lógica alterada para a modalidade interativa de comunicação. $O$ receptor passa a ser emissor, ou vice-versa. Sobre essa interação, Marcos Silva constrói um panorama teórico $(2002$, p. 86), sobre os níveis, graus e dimensões permitidas pela interação. Há uma diferenciação do termo interatividade em três modalidades: uma baseada na seleção de conteúdos; b) outra baseada na intervenção sobre conteúdos; c) a terceira tomando os dois processos anteriores em conjunto - a "mista".

Dentre esses casos, a interatividade com o grau mais elevado é a "mista", devido ao nível de troca informacional, um exemplo é o CD-ROM, hipermídia que permite a intervenção sobre os textos apresentados - as telas-página, como o próprio Silva denomina. Todavia, essa interatividade é limitada, pois esgotam-se em si mesmo. Porém, o acesso de páginas prontas e a flexibilidade para recompô-las, segundo nossas necessidades, efetivou-se definitivamente com o aparecimento do hipertexto - diversos links que permitem uma ação contínua do sujeito-autor e provavelmente única.

A partir dos estudos de Marcos Silva, Alex Primo propõe avanços aos estudos relacionados à interação mediada por computador. De certa forma, sua proposta faz-se uma extensão dos estudos de Silva. Determinam-se dois tipos de interação: a mútua e a reativa. A interação mútua é aquela "caracterizada por relações interdependentes e processos de negociação, em que cada interagente participa da construção inventiva e cooperada do relacionamento, afetando-se mutuamente" (2006, p. 99). Percebe-se que a maior evidência no ciberespaço de interação é do tipo mútua. Já a interação reativa é limitada por relações determinísticas de estímulo e resposta. Nas palavras de Primo, essa interação se descreve "por uma forte roterização e programação fechada (já préestabelecida) que prende a relação em estreitos corredores, onde as portas sempre levam

\footnotetext{
${ }^{3}<$ http://www.facom.ufba.br/ciberpesquisa/andrelemos/remix.pdf> Acesso, em: 26 out. 2008.

4 Termo de Maffesoli que exprime a relação entre as novas tecnologias e a sociedade contemporânea. $<$ http://ucsnews.ucs.br/ccha/deps/cbvalent/EAD/homepsico/andre.html> Acesso, em: 29 out. 2008.

V. $7 \mathrm{~N}^{\circ}$ 3, dezembro, 2009
} 
a caminhos já determinados à priori” (2006, p. 135) - a grosso modo, a relação reativa cerceia a tão "sonhada" liberdade inerente à rede".

De maneira geral, a interação pode ser conceituada como "relações e influências mútuas entre dois ou mais fatores, entes etc. Isto é, cada fator altera o outro, a si próprio e também a relação existente entre eles" (Primo, 2006, p. 197). Então, a interatividade é um caso específico de interação e se aproxima dos conceitos dados por Primo de interação mútua.

A interatividade se torna mais presente nos textos eletrônicos. Os cruzamentos e bifurcações otimizados pela rede ampliam o leque de possibilidades. Uma construção rizomática dos sentidos. Próximo da interação mútua, a interatividade não se encerra no ato de troca, nem na interação digital - de cunho rizomático, ela torna-se mais e mais presente por esse caráter aberto à comunicação, uma relação ilimitada de troca e uma participação mais ativa do sujeito, diferente da simples interação.

Há, portanto, o signo-texto (verbal ou não-verbal) - signo como aquilo que está no lugar de outra coisa - que é a materialidade do diálogo para o processo de interação. Falar de texto implica falar de linguagem, de leitura, de textualidade, de interlocução e de condições de produção. Segundo Brandão (2001), o texto é uma unidade de sentidos possíveis, cuja primeira atribuição de sentidos é dada pelo próprio autor num gesto de interpretação, que está diretamente relacionado à memória de dizer ao interdiscurso.

A partir dessas características, postulou a urgência por um software educacional capaz de possibilitar o ensino/ aprendizagem, propiciando aos professores e aos alunos novas formas de aprender e ensinar (on line). Nesse caso, o Moodle. Um software livre, que significa autonomia para usar, copiar, distribuir, criar, modificar, comercializar e gerenciar seus próprios recursos. Esse software, além de ser uma ferramenta de gestão de cursos a distância, é desenhado para ajudar educadores a criar, com facilidade, cursos on line de qualidade.

Diante desse cenário, Castells (2002) defende que a atual sociedade em rede exige um repensar sobre as certezas que tínhamos sobre a comunicação mediada. Afinal, constata-se que os meios digitais abrem novas formas de comunicação e demandam uma reconfiguração dos meios tradicionais, ao mesmo tempo que amplificam potenciais pouco explorados.

Parte dessa metamorfose comunicacional permeia também os conceitos de leitura e leitores. Segundo Santaella (2006), os leitores podem ser classificados em Contemplativo, ou Meditativo; Movente ou Fragmentado; e Imersivo ou Virtual: o primeiro pode ser identificado como o leitor de todas as formas de texto impresso: livros, jornais, revistas, folhetos, folders etc. O segundo leitor a partir da segunda metade do século dezenove com a produção serial dos objetos, o viver significa compartilhar complexidade como telégrafo, telefone, dentre outros; De acordo com Santaella (2006, p. 33), "o leitor contemporâneo é o leitor Imersivo, ou Virtual. Trata-se de um modo inteiramente diferente de ler. Esse leitor se difere do leitor contemplativo e do leitor movente, pois não se trata mais de um leitor que tropeça, esbarra em signos físicos, materiais - como é o caso do leitor movente"; Um leitor movente ${ }^{5}$, cuja subjetividade se mescla na hipersubjetividade de infinitos textos, num grande caleidoscópio tridimensional, onde cada nó e nexo podem conter outra grande rede numa outra dimensão.

A par de todo esse pressuposto teórico da comunicação e educação a distância, seguem as análises sobre os chats, fóruns e entrevistas on line (via e-mail) feitas para

\footnotetext{
${ }^{5}<$ http://www.pucsp.br/pos/cos/epe/mostra/santaell.htm> Acesso, em: 27 nov. 2008.
} V. $7 \mathrm{~N}^{\circ}$ 3, dezembro, 2009 
verificar a produção de sentidos na não-presença entre os cursistas e tutores no ensino/ aprendizagem do NEAD/ UFMT, do curso de Formação Continuada, Turma 4.

Vale ressaltar que as falas dos entrevistados vão ser mantidas ipsis litteris na transcrição desse trabalho, com erros e pausas, assim como se expressaram os envolvidos via chat, fórum e entrevistas. A amostra de fórum selecionada para análise foi a proposta na Unidade I/ Módulo I, intitulada "Os Caminhos da Educação a Distância no Brasil". O tutor desse módulo foi o professor Oresti Preti.

A dinâmica do fórum funcionou da seguinte forma: Primeiro, fez-se a leitura do texto-base. Um texto homônimo ao módulo: "Os Caminhos da Educação a Distância no Brasil". No texto, introduziu-se a noção de Ensino a Distância aos cursistas e foram mostradas as perspectivas dessa modalidade de ensino. Em um segundo momento, propôs-se avaliações, bate-papos e fóruns para a socialização de idéias, impressões sobre o texto e apontamentos sobre o tema. O tutor levantou temas pertinentes ao textobase e à Formação crítica desses leitores e propôs a troca de informações entre os participantes:

Diante das questões enunciadas abaixo, bem como o registro de suas reflexões, participe do debate e poste suas contribuições. Proponho que, ao final da leitura desse tópico, reflita e produza texto-síntese sobre os caminhos da EaD no Brasil, buscando dar conta das seguintes indagações: Por que somente agora o governo colocou a $\mathrm{EaD}$ não mais como algo periférico, mas como parte do sistema educacional? Quais são suas prioridades no campo da EaD? Quem se beneficia com essa modalidade? (Presti, 2008).

A partir desses pontos-guia propostos por Presti aos cursistas, os leitores deveriam argumentar sobre a $\mathrm{EaD}$, sob o prisma desses três aspectos citados acima. $\mathrm{E}$ assim começam as discussões:

(...) Chegamos a um tempo em que não dá mais para tampar o sol com a peneira, é perceptível que o governo não conseguirá tirar em uma ou duas décadas o desnível educação ao qual estamos submetidos, então, partindo desse princípio, rendeu-se a essa maravilhosa ponte que é o "estudar a distância", esse nada mais é que um termo usado para distinguir uma forma de estudar da outra(presencial), mas que na verdade não existe nada distante, pois a vontade e o querer saber, está dentro de cada um de nós e o que faltava era um pouco mais de acesso(...)Quanto as prioridades, já observei que, primeiramente é suprir o mercado de trabalho com alguns cursos bases na àrea da educação(matemática/ciências, Química, Física, administração, pedagogia e cursos na àrea da informática. Todos nós nos beneficiamos, principalmente quem nunca teve como entrar em uma Universidade com a UFMT por exemplo, mas os governos também se beneficiam, pois terão mais profissionais gabaritados, com isso todos nós ganhamos, a qualidade dos serviços prestados passa a ser observado e desejado também por outros municípios e assim por diante (cursista Gean Marcos de Oliveira Moraes - do NEAD/ UFMT, 2008).

O cursista atende a proposta pretendida pelo fórum e constrói sentidos condizentes ao texto-base, indo além, utilizando exemplos contextualizados com a nossa realidade. Contudo, quando argumenta sobre as prioridades da $\mathrm{EaD}$ e sobre quem se beneficia com essa modalidade, limita-se a responder: “(...) é suprir o mercado de trabalho" e " "estudar a distância', esse nada mais é que um termo usado para distinguir uma forma de estudar da outra (presencial)", respectivamente.

É aí que entra a figura do tutor para mediar, orientar, facilitar o diálogo entre o texto e o aluno, contribuindo na construção de sentidos pretendidos. A tutora, após apresentar-se aos cursistas, indica:

Olá Aluno A, sou Lucia Helena, a tutora de sua turma É com muita satisfação que começo com você a discussão sobre o que está proposto. Você tem toda razão, pela educação presencial, tão cedo não conseguiríamos dotar o mercado de profissionais. Mas há outro ponto muito importante: o da capacitação, onde cada um dos cursistas é autônomo no seu espaço e no seu tempo, para construir conhecimento.A experiência de se estudar em EAD é única, pois se difere das demais, uma vez que cada um fará, a partir de suas histórias de leituras, seu roteiro de estudo, estabelecerá suas prioridades, juntamente com a tuora e 
com os colegas, construirá sentidos/conhecimento no coletivo. Espero você mais vezes e, por favor, incentive seus colegas. Atenciosamente, Lucia Helena (Lúcia Helena, 2008).

A professora que medeia esse fórum, aponta as partes que devem ser ampliadas na argumentação do cursista A. Aspectos como "o da capacitação, onde cada um dos cursistas é autônomo no seu espaço e no seu tempo para construir conhecimento" e "a experiência de se estudar em EaD é única, pois se difere das demais, uma vez que cada um fará, a partir de suas histórias de leituras, seu roteiro de estudo, estabelecerá suas prioridades, juntamente com a tutora e com os colegas, construirá sentidos/conhecimento no coletivo" fundamentam a contra-argumentação da tutora no sentido de esclarecer esses aspectos que ainda permaneciam nublados ao cursista.

A outra análise foi sobre o chat, uma espécie de conversa informal mantida via Internet, uma das ferramentas abraçadas pelo núcleo. Na plataforma, o chat também tem o intuito de troca informacional, só que com outro viés, o de fomentar a educação. No curso a distância utiliza-se o chat como um dos diversos recursos de comunicação, possibilitando a aprendizagem colaborativa: as pessoas podem interagir com os colegas e professores utilizando tais recursos. As ferramentas de comunicação do NEAD são assíncronas, exceto o Bate-papo. A comunicação assíncrona é a transmissão de dados sem utilização de um sinal de sincronia (chamado de relógio).

Sobre esse tipo de interação, cabe aprofundar o conceito de telepresença, indicado por Araújo. Segundo a autora, a telepresença depende de um suporte tecnológico que permita, em tempo real, a comunicação dialógica e a interação. Podemos dizer, por exemplo, em relação ao Bate-papo do NEAD, que ele é uma forma de telepresença: não possui limite de número de participantes, nem de caracteres por enunciado, é síncrono e assim por diante. No entanto, é por meio de sua utilização que se pode ajustar os parâmetros de acordo com as necessidades de um grupo de usuários e/ou combiná-los de forma a produzir outra modalidade de comunicação mediada.

Com base nesses conceitos, a pesquisa foi focada no chat realizado na plataforma do NEAD, no dia oito de setembro às 18:00 horas, uma segunda-feira. Devese ressaltar que as sessões de Bate-papo são agendadas previamente e registradas: qualquer participante do curso pode ter acesso aos registros para posterior análise da discussão. Assim, começou-se o debate: “(...) Bem, nossa 3a. unidade fala sobre a produção de material para EAD. Vc gostou da unidade? Comente alguns aspectos. Encontrou alguma dificuldade ? sobre qial o lugar do Material em EAD; como produzir o não-verbal e depois diferenciamos um texto base de guia didático". Segue abaixo alguns depoimentos sobre o texto-base:

17:36 Anderson: so nao li o texto de aprender mais o base eu li

17:39 Edicleia: Estou lendo os materias, este módulo está muito díficil administrar o meu tempo.

17:40 Dr. ${ }^{a}$ Lúcia Helena: Como dissemos, o material é a única corporeidade que liga o autro/tutor e vcs. Assim, ele tem que ser pensado dentro de condições de produção: para quem? com que objetivo?, o quê? e, ainda a função dele no curso como um todo.

A tutora motiva os alunos a participarem do bate-papo e os instiga a retomar os textos e leituras propostos na plataforma Moodle para enriquecer o chat e construir, de fato, um conhecimento colaborativo. Sobre o material (textos on line ou impressos, imagens etc.) voltado à Educação a Distância os cursistas argumentam:

17:42 Anderson: Tem q se levar em consideração o conhecimento da pessoa a quem $c$ destina o material $p / q$ nao exista um desinteresse do aluno

17:44 Dr. ${ }^{a}$ Lúcia Helena: Tem tb que esgotar nele mesmo todas as questões e resolvê-las, pois é ele a única materialidade e o professor não está presente, no momento em que o aluno o está lendo.

17:47 Anderson: esse material tem que gerar um interesse no aluno em buscar o conhecimento ja q geralmento o aluno vem de uma aprendizagem presencial onde o professor esta ali acompanhando seu desenvolvimento no decorrer do seu curso

V. $7 \mathrm{~N}^{\mathrm{o}}$ 3, dezembro, 2009 
17:50 Dr. ${ }^{a}$ Lúcia Helena: Como se vê, além de ser escrito, para ser veiculado por impresso, ou no caso de vcs, na plataforma, pode-se tb produzir mateirial em áudio e em audiovisual. o que acham?

17:51 Anderson: Já na EaD é o aluno q faz seu tempo, seu estudo e nesse perido o mais proximo q chegamos dele é atraves do material didatico, material esse q precisa ser muito bem trabalhado visando favorecer a compreensão do q foi colocado. Pela plataforma acho muioto interessante, mas c fosse em audiovisual c tornari mais atrastivo p/o aluno.

Os aluno argumenta sobre a importância do material didático e contra-argumenta dizendo que a linguagem que for aplicada ao material tem que ser interessante e atrativa. Nesse sentido, a tutora questiona sobre outras linguagens, como a não-verbal, por exemplo (vídeos, sons, imagens) - afinal o ciberespaço é um meio híbrido, uma convergência midiática -, e os alunos respondem:

(...) 17:52 Dr. ${ }^{a}$ Lúcia Helena: pode ser uma gravação de uma aula, pode ser uma videoconfer6encia, pode ser só áudio, para os deficientesvisuais, pode ser só video para deficiente auditivos, podem ser ambos com experiências, vídeos de outros autores, enfim...

17:55 Edicleia: è uma forma de oportunizar a ampliação do conhecimento do aluno, pois, nem todos conseguem atiingir o objetivo necessário apenas com a leitura do fascículo, estaria beneficiando essas pessoas

17:57 Anderson: então alguns alunos tem uma certa dificuldade na interpretação da escrita e ja na audio ou audiovisual isso ajudaria este aluno na absorção do conhecimento

As respostas dos cursistas sobre adotar outras linguagens para a Educação a Distância são bem positivas. Como cada indivíduo tem uma habilidade de leitura, faz-se importante a utilização de diversas linguagens, além de ser mais atrativo. Sobre entrevistas com os tutores foram feitas via e-mail. A partir delas, traçou-se o perfil desses tutores, além de destacar os aspectos comportamentais dos envolvidos nessa modalidade de ensino/ aprendizagem a partir do depoimento dos mesmos. Do perfil dos entrevistados - TUTORES:

1- a) Há Tutores que produziram o material do curso (veiculado on line); b) Há Tutores apenas, que não são autores do material;

2- Todos os tutores trabalham com a EAD há mais de 2 anos;

3- a) A maior parte dos tutores é formado em Educação com Mestrado nessa área; b) Um dos tutores é formado em Letras com doutorado em Comunicação.

A primeira questão levantada na entrevista foi sobre a Educação a Distância, sobre como os tutores percebiam a Educação a Distância, como definiam e/ou conceituavam essa outra modalidade de ensino, já que estavam diretamente se relacionando por meio dela. A opção de resposta era livre para todas as questões. Como já destacamos, todos os tutores têm no mínimo dois anos de experiência no NEAD, então, alguns preferiram se ausentar dessa resposta por considerá-la enfadonha.

Meu conceito é o mesmo de Educação, porque na EAD o que fazemos é fundamentalmente Educação, numa modalidade diferente da presencial. Educação a considero como prática social que busca formar o cidadão, desenvolvendo consciência crítica, competências $e$ habilidades para intervir e modificar o contexto em que está inserido" (Entrevista Oresti, 2008).

A partir das respostas colhidas, categorizamos o maior índice em respostas sobre esse conceito $(\mathrm{EaD})$. Os discursos que se destacaram foram: a) que o EaD contribui para a construção do conhecimento para formação do cidadão; b) que a construção desse ensino não necessariamente se dá na simultaneidade; c) que o EaD não se relaciona com a questão de como se construir conhecimento; d) que o EaD se difere da Educação Presencial. Na segunda pergunta, questionamos sobre a participação dos cursistas no Núcleo a distância, se eram freqüentes e a contento. Assim, argumentou Lorensini: COMO EM TODO PROCESSO EDUCATIVO SEJA NA MODALIDADE PRESENCIAL, SEMI-PRESENCIAL OU NÃO PRESENCIAL TEMOS ALUNOS QUE SE ENVOLVEM E AQUELES QUE NÃO SE ENVOLVEM, NO SEGUNDO CASO, PODEMOS OFERTAR O MELHOR DOS CURSOS COM CORPO DOCENTE QUALIFICADO, CONDIÇÕES SATISFATÓRIAS, CONTEÚDO INTERESSANTE, QUE DIFICILMENTE

V. $7 \mathrm{~N}^{\mathrm{o}}$ 3, dezembro, 2009 
CONSEGUIREMOS UMA PARTICIPAÇÃO EFETIVA DO CURSISTA. TAMBÉM NÃO PODEMOS SOMENTE DELEGAR A RESPONSABILIDADE AO CURSISTA, NA MODALIDADE A DISTÂNCIA NECESSARIAMENTE HÁ QUE SE TER UM MOVIMENTO DE ESTUDO E CONSEQÜENTEMENTE DE ORIENTAÇÃO MEIO QUE SINCRONIZADO, E ISSO É DIFÍCIL UMA VEZ QUE TUTOR E ALUNO PODEM NÃO TER ESSA SINCRONIA, COMO TUDO TEM INÍCIO, MEIO E FIM, O TEMPO HÁBIL MUITAS VEZES NÃO PERMITE UM AJUSTE PARA QUE EFETIVAMENTE AS PESSOAS SE ENVOLVAM O SUFICIENTE PARA DESENVOLVER UM PROCESSO DE APRENDIZAGEM SATISFATÓRIO (2008).

De acordo com as respostas dos tutores sobre a participação dos cursistas dentro do Moodle, podemos chegar às seguintes constatações, no que diz respeito ao envolvimento do cursista, à sua capacidade de responder às questões e realizar as tarefas a contento: a) há algum envolvimento dos cursistas, mais no fórum que nos chats. As tarefas e as atividades finais de produção de material são a contento; b) para esses professores, quase não há envolvimento dos cursistas. Durante as respostas da entrevista, os tutores apresentaram algumas razões para o não envolvimento dos cursistas nesse ambiente educacional: a) falta de habilidade em lidar com o ambiente Moodle; b) Falta de tempo para realizar tarefas e atividades; c) inabilidade para estudar e construir por si sós e participar das redes, oportunizadas pelo ambiente on line. Após esse apanhado de dados sobre o desempenho dos cursistas, questionamos os tutores sobre como eles acreditavam que os alunos podiam atribuir sentidos - ler - e, portanto, cumprir tarefas e executar atividades na não-presença. Segue uma resposta:

ADULTO APRESENTA UMA CAPACIDADE MENTAL ESTRUTURADA, ENTRETANTO ESTA É PASSÍVEL DE MELHORA E AMPLIAÇÃO.

A POSSIBILIDADE DE FAZER COISAS PASSA PELA CAPACIDADE DA AUTONOMIA DE PENSAMENTO E AÇÃO, A DE DAR SENTIDOS PASSA TAMBÉM PELA AUTONOMIA DE PENSAMENTO E AÇÃO MENTAL ACRESCIDA DE SENTIDOS E PERCEPÇÕES HISTORICAMENTE ELABORADOS NO COTIDIANO DE CADA UM. EM UM PROCESSO DE QUALIFICAÇÃO, DADAS AS CAPACIDADES ACIMA MENCIONADAS NOS COMPETE DIRECIONAR O PROCESSO DENTRO DAQUILO QUE CONSIDERAMOS ESSENCIAL, SEMPRE PENSANDO NA IMPORTÂNCIA E PRINCÍPIOS QUE SUSTETAM DETERMINADO CONHECIMENTO (Sandra, 2008).

Nota-se no discurso de ambos os professores o domínio e clareza de idéias sobre a Educação a Distância. Os entrevistados são unânimes em responder que o caráter dialógico empregado na Educação a Distância, por meio dos Fóruns e Chats, é de fundamental relevância para o desenvolvimento e aprendizagem dos alunos e para a efetivação da interatividade entre os envolvidos. Para tanto, faz-se necessário o domínio das ferramentas virtuais. E esse é um dos grandes entraves encontrado por esse formato educacional (on line). Do perfil dos entrevistados - CURSISTAS:

1- Todos são professores (condição para fazer o curso);

2- Todos residem no interior;

3- a) Alguns têm apenas uma graduação em Licenciatura; b) Outros têm duas graduações (Licenciatura e Bacharelado);

4- Todos lecionavam em escolas de seus municípios, por mais de seis meses.

Com o intuito de sanar essa barreira metodológica, os tutores tentam motivar seus alunos por meio do uso de diversas linguagens (textos, imagens, vídeos etc.), e de cursos que ofereçam noções básicas de informática, para tornar atrativo e praticável a EaD. Por último ocorreram as entrevistas com os cursistas. Elas se deram de forma totalmente on line. Enviou-se o questionário com algumas indagações sobre essa modalidade de ensino aos cursistas e tutores e aguardamos as respostas. O primeiro aspecto questionado na entrevista com os cursistas foi também sobre a Educação a Distância, até para termos um parâmetro entre os dois constituintes dessa modalidade. $\mathrm{O}$ cursista $\mathrm{A}$, que preferiu não revelar a identidade, respondeu da seguinte forma: 
EaD significa ir onde o aluno está, ser um processo mediado por tecnologia, oferecer horários alternativos de aprendizagem, trazer uma reflexão nova para o ensino, garantindo oportunidades $e$ promovendo justiça social (cursista A, 2008).

Com as respostas de todos os entrevistados em mãos, categorizamos os conceitos sobre Educação a Distância mais freqüentes entre os participantes do curso: a) que o EaD elimina distâncias, além de construir cidadãos; b) que o EaD se apresenta como uma alternativa para a formação do indivíduo; c) que o EaD se difere da educação presencial. Já na outra pergunta, questionamos sobre a concepção de leitura dos cursistas. Segue algumas respostas:

É uma atividade básica na formação cultural da pessoa. A leitura é fundamental para a compreensão do conhecimento, pois é através da leitura continua que construímos e reformulamos nossas idéias, no ato da leitura desvendamos sentidos e descobrindo o mundo, o que leva a produzir novos textos (cursista C, 2008).

A LEITURA É O ESSENCIAL PARA QUALQUER CIDADÃO (cursista D, 2008).

Como podemos notar, há respostas mais aprofundadas em detrimento de outras genéricas. Esse é o caso da primeira e da segunda entrevista acima, respectivamente. $\mathrm{O}$ entrevistado $\mathrm{C}$ demonstra o quanto é consciente sobre o papel social da leitura, no entanto, não relaciona essa leitura ao campo da Educação a Distância. Em contrapartida, o entrevistado D apresenta uma resposta vaga e generalizante. A terceira pergunta foi sobre o desempenho dos participantes. Obtivemos as seguintes respostas: a) Muito bom; b) Bom; c) Regular. A maioria dos entrevistados se considera um aluno bom, por participar das atividades e interagir com freqüência com os tutores. Os que se julgam com um desempenho Muito Bom são os que participam mais ativamente das atividades e constantemente acessam a plataforma. Quanto aos alunos que se consideram Regulares, a justificativa é por não dominarem as ferramentas da Web ou por alegação de ausência de tempo para o devido acesso à página do NEAD.

A sugestão dos cursistas para melhorar a partição e a interação foi: “(...) acredito que melhoraria nosso desempenho se tivéssemos outros formas de contato como, por exemplo, as videoconferências"; ou, “(...) tenho apenas um pouco de dificuldade de perceber o que meu tutor quer na forma como está o curso. Penso que seria melhor se tivéssemos alguns encontros presenciais, principalmente sobre os assuntos que envolvem política. Talvez videoconferência". Percebe-se que os cursistas querem encontros presenciais mediados pela Web. O uso de videoconferências é uma forma de se tele-projetar, simultaneamente, para o outro. Esse recurso de linguagem também é utilizado pelo NEAD. Por fim, pedimos aos entrevistados algumas críticas e sugestões sobre esse método de ensino, sobre a interação e a produção de sentidos que ele proporciona. Seguem as respostas:

Não houve dificuldade em relação à utilização de ferramenta (moodle).Com textos mais interativos, com questões, auto reflexões e vídeos interativos é possível ler, atribuir sentidos ao texto, realizar atividades na não presença autor/tutor/cursista.A proposta do curso é muito interessante, o material é bom, só sinto falta da discussão em grupo e de alguns encontros presenciais" (cursista A, 2008).

(...) as leituras devem ser claras e precisa e sendo capaz conduzir o aluno a raciocinar de forma coerente e de acordo com o propósito do professor. Acho imprescindivel alguns encontros presenciais ou vídeo- conferência. (...) acredito ser possível aprender a distância, mas é necessário algum tipo de presencialidade, para haver um envolvimento emocional,criar laços, e ainda sentir o calor humano, não somente o computador. proporcionar ao estudante algumas palestras sobre temas em que sintam maiores dificuldades (cursista B, 2008).

Nas respostas acima, evidencia-se nas falas dos cursistas uma dificuldade no lidar com aulas não-presenciais. Paradoxalmente, todos responderam que com a leitura dos textos (verbais e não-verbais) conseguem atribuir sentidos mediados pelo computador. Revela-se, então, um dado novo. Os alunos têm dificuldades na leitura dos textos, assim como nas aulas presenciais. Os alunos também têm dificuldades em V. $7 \mathrm{~N}^{\circ} 3$, dezembro, 2009 
manusear as ferramentas da Web. Mas o fator cultural é o que mais chama a atenção. Por os cursistas estarem acostumados às aulas presenciais, monológicas, hierárquicas e pouco interativas, eles sentem dificuldades em interagir nessa nova dinâmica educacional que não necessita da presença física.

\section{Considerações finais}

Após todas as análises, percebe-se que há uma efetiva troca simbólica entre os interagentes: cursistas e tutores. Mas apesar das ferramentas utilizadas (Fórum, batepapos) serem satisfatórias, são insuficientes para o aprendizado, assim como argumentaram os entrevistados. Como o ciberespaço é um meio híbrido por excelência, uma mescla, uma convergência midiática, faz-se notório que se amplie os horizontes educacionais e aplique uma injeção de ânimo para que outras linguagens (vídeo, áudio etc.) sejam adotadas nessa nova modalidade educacional - o que já ocorre, mas timidamente.

Para isso, cabe aos profissionais de educação e de comunicação repensarem essa nova abordagem educacional via Web, produzindo textos (verbais ou não-verbais) com intuitos educacionais, que visem sentidos pretendidos ao ensino/ aprendizagem e um desempenho positivo dentro do curso. Outro ponto importante é a leitura. Ler para o ensino/ aprendizagem é fundamental e, no ciberespaço, faz-se mais fundamental ainda. Se lembrarmos que o sujeito nessa modalidade educacional não-presencial se corporifica via texto, como não ler?

Notamos, então, que uma das barreiras ainda é a leitura. Os cursistas não se dedicam a leitura com afinco para ter um bom rendimento no curso. O que não é muito diferente dos cursos presenciais! Uma profunda mudança cultural faz-se necessária para estimular a prática da leitura, para que assim, se desenvolva outras habilidades desses alunos (como a interpretação, escrita etc).

\section{Referências}

ARAUJO, Y. Rondon. Telepresença: interação e interfaces. São Paulo: EDUC, 2006.

BARBERO, Jesús-Martin. Dos meios as mediações: comunicação, cultura e hegemonia. Rio de Janeiro: UFRJ, 2002.

BARROS, Manoel. O livro sobre o nada. São Paulo: Record, 2006.

BRANDÃO, Maria Helena Nagamine. Introdução a análise do discurso. São Paulo: Unicamp, 2001.

CASTELLS, Manuel. A sociedade em Rede - a era da informação: economia, sociedade e cultura. São Paulo: Paz \& Terra, 2002.

GEERTZ, Clifford. A interpretação das Culturas. São Paulo: Ltc, 1973.

LEMOS, André. Cibercultura - tecnologia social na cultura contemporânea. Porto Alegre: Sulina, 2007.

LÉVY, Pierre. Cibercultura. Trad. Carlos Irineu da Costa. São Paulo: 34, 1999.

MORAES, Denis (Org.). Sociedade Midiatizada. Rio de Janeiro: Mauad, 2006, p. 71.

MORAES, Maria Cândida. O paradigma Educacional emergente. Campinas, São Paulo: Papirus, 1997.

MORIN, Edgar. Ciência com consciência. Trad. Maria D. Alexandre e Maria Alice Sampaio Dória. Rio de Janeiro: Bertrand Brasil, 1996.

POSSARI, L. H. V. Comunicação e informação em EAD. Curitiba: NEAD/UFPR, 1999.

PRIMO, Alex. Interação mediada por computador: comunicação, cibercultura, cognição. Porto Alegre: Sulina, 2006.

SANTAELLA, Lucia. Navegar no ciberespaço - o perfil cognitivo do leitor imersivo. SP: Paulus, 2006.

SILVA, Marco. Sala de aula Interativa. Rio de Janeiro: Quartet, 2002. 